\section{PENELITIAN PENGGUNAAN PARAFFINIC OIL PERTAMINA SEBAGAI MINYAK PELUNAK KOMPON KARET} UNTUK SOL SEPATU KANVAS

Sofyan Karani, Prayitno, Adi Slamet S,HY. Supardal

\section{ABSTRACT}

The objective of the research is to use parafinic oil, by product of ertamina, as a softener in making rubber sole compound for canvas shoes. he formula of the compound applled two kinds of parafinic oil, namely araffinic 60 and paraffinic 95 with variation $2-8 \mathrm{phr}$. The mastication and ixing processes used two roll mill machine and the compound was Ilcanized at $150{ }^{\circ} \mathrm{C}$, at the pressure $150 \mathrm{~kg} / \mathrm{cm}^{2}$ and 10 minutes curing time. he comformityt of softener, paraffinic oil, is excellent and no oil exist to the irface of the vulcanized compound. The property of the vulcanized mpound fulfilled all the quality requirements of SNI 0778 - 89 - A and SNI 344 - 90 - A for canvas shoe rubber sole, except abrassion for sport shoe nax. $1.00 \mathrm{~mm}^{3} / \mathrm{kgm}$ compared with the result of the tes, $1.36-2.32$ $\mathrm{m} 3 / \mathrm{kgm}$ ). Data analysed proves that the addition of paraffinic oil in rubber mpound decreased tear strenght and tensile strenght. The properties of ongation at break, permanent set, hardness, abrassion, density and flexing significant defferences between kinds, types and the treatment of raffinic oil Pertamina as a softener in rubber compound.

\section{INTISARI}

Penelitian ini bertujuan untuk memanfaatkan paraffinic oil Pertamina bagai bahan pelunak dalam pembuatan kompon karet untuk soal sepatu nvas. Formula kompon menggunakan dua jenis paraffinic oil yaitu parafic 60 dan paraffinic 95 dengan variasi antara $2-8$ phr. Pencampuran enggunakan giling karet terbuka dan kompon divulkanisasi pada suhu 150 , tekanan $150 \mathrm{~kg} / \mathrm{cm}^{2}$ dan waktu 10 menit. Tingkat kecocokan bahan peluk paraffinic oil sangat baik, tidak terjadi pengeluaran minyak ke permukakompon dan vulkanisat kompon. Sifat vulkanisat memenuhi semua peraratan mutu dalam SNI 0778 - 89 - A dan SNI 1844 - 90 - A untuk sol karet patu kanvas, kecuali syarat mutu ketahanan kikis sol sepatu untuk olah ga maks. $1,00 \mathrm{~mm}^{3} / \mathrm{kgm}$ dibandingkan dengan hasil uji kikis vulkanisat itu antara $1,36-2,32 \mathrm{~mm}^{3} / \mathrm{kgm}$. Hasil analisa data uji menunjukkan bah. penambahan paraffinic oil dalam kompon karet akan menurunkan sifat kuatan tarik dan kekuatan sobek. Sedangkan sifat perpanjangan putus, rpanjangan tetap, kekerasan, ketahanan kikis,berat jenis dan ketahanan ak lentur tidak menunjukkan perbedaan yang nyata antara jenis, type dan iakuan paraffinic oil Pertamina sebagai minyak pelunak dalam kompon iet.
Karet mentah merupakan bahan yang ulet, kuat dan liat maka dalam proses pencampuran dan pengolahan memerlukan pelunakan dan panas serta tenaga yang intensif sehingga pencampuran bahan pembantu lebih mudah dan dalam waktu yang lebih singkat dalam proses pencampuran. Bahan pelunak adalah bahan yang berfungsi untuk memudahkan pencampuran bahan pengisi dan meningkatkan penyebaran bahan pengisi dalam kompon karet. Sehingga proses pencampuran dapat dilakukan pada suhu relatif rendah untuk menghindari terjadinya schorsing pra-vukanisasi. $(3,4)$

Sebagian besar minyak pelunak (softener) yang digunakan dalam in dustri karet dalam negeri masih di import dan kebutuhan setiap tahun terus meningkat sesuai dengan perkembangan industri perkaretan di Indonesia Didapat beberapa merek yang memenuhi pasaran dalam negeri, yaitu Dutrex buatan Sheel, Ku Dong buatan Korea, Gulf Processing oil dan Mobil sol buatan Amerika Serikat. (1)

Untuk mengantisipasi hal tersebut dan dalam usaha menaikan nila tambah produk ekstrak dan mengoptimalkan operasi kilang Pertamina. Per tamina telah menghasilkan dan memasarkan dua produk baru yang dihasilkan oleh kilang minyak Unit Pengelolaan IV Pertamina di Cilacap, Yaitu : 1. minyak pelunak aromatik atau Aromatic Processing Oil dengan merek dagang MINAREX, 2. minyak pelunak parafinik atau Paraffinic oi yang diproduksi Pertamina ada dua jenis yaitu : PARAFFINIC 60 dan PARAFFINIC 95. (2)

Ada tiga golongan minyak pelunak yang berasal dari pengolahan mi nyak bumi yaitu : minyak parafinik, minyak naftanik dan minyak aromatik, dimana masing-masing golongan mempunyai pengaruh yang spesifik pada kompon dan barang jadinya. (5)

Dalam rangka penerapan penggunaan minyak pelunak hasil Pertami na dalam industri barang karet dan plastik, Pertamina telah melakukan kerja sama penelitian antara Pusat Pengendalian Mutu Petrokimia Pertamina Jakarta dengan Balai Besar Penelitian dan Pengembangan Industri Barang Kulit, Karet dan Plastik Yogyakarta. Salah satu penelitiannya adalah Penggunaan paraffinic oil Pertamina sebagai minyak pelunak (softener) dalam pembuatan kompon karet untuk sol sepatu kanvas.

\section{BAHAN DAN METODA}

\section{Bahan}

Bahan paraffinic oil yang digunakan untuk mengamati pengaruh penggunaannya dalam kompon karet sebagai bahan pelunak untuk sol sepatu kanvas ada 2 jenis dan 2 type yaitu :

VOL VIII No. 15 Tahun 1992/1993 
1. Jenis paraffinic 60

- type paraffinic 60.2

- type paraffinic 60.3

2. Jenis paraffinic 95

- type paraffinic 95.3

- type paraffinic 95.3

Formula yang digunakan dalam penelitian ini dapat dilihat dalam tabel 1, dimana variasi bahan pelunak paraffinic oil dalam kompon untuk masing-masing jenis dan type adalah 2,5 dan 8 perseratus berat karet ( $\mathrm{phr}$ ).

Tabel 1. Formula kompon karet untuk sol sepatu

\begin{tabular}{|r|l|c|c|c|}
\hline No. & \multicolumn{1}{|c|}{ Bahan } & Kompon A & Kompon B & Kompon C \\
\hline 1 & Pale Crepe & 80,0 & 80,0 & 80,0 \\
2 & SBR & 20,0 & 20,0 & 20,0 \\
3 & Kalsium Karbonat & 30,0 & 30,0 & 30,0 \\
4 & Alumunium silikat & 40,0 & 40,0 & 40,0 \\
5 & Zink oksida & 4,0 & 4,0 & 4,0 \\
6 & Asam stearat & 1,5 & 1,5 & 1,5 \\
7 & Tin oksida & 1,0 & 1,0 & 1,0 \\
8 & Zat warna & 0,5 & 0,5 & 0,5 \\
9 & Paraffinic oil & $(2,0)$ & $(5,0)$ & $(8,0)$ \\
10 & Anti oksida & 1,0 & 1,0 & 1,0 \\
11 & MBT & 0,7 & 0,7 & 0,7 \\
12 & MBTS & 0,4 & 0,4 & 0,4 \\
13 & TMT & 0,5 & 0,5 & 0,5 \\
14 & Sulpur & 2,5 & 2,5 & 2,5 \\
\hline
\end{tabular}

\section{Metoda}

Proses pencampuran bahan kimia dalam pembuatan kompon dilakukan dengan menggunakan mesin penggiling karet terbuka (two roll mill) pada suhu giling sekitar $70^{\circ} \mathrm{C}$ sebanyak 36 kali komponding.

Setelah pembuatan kompon selesai, kompon di aging selama 24 jam dalam ruang kondisi. Tahap berikutnya dilakukan proses vulkanisasi dengan kondisi proses suhu $150^{\circ} \mathrm{C}$, tekanan $150 \mathrm{~kg} / \mathrm{cm}^{2}$ dan waktu 10 menit untuk mengetahui sifat-sifat kompon karet.

Penguji sifat fisis kompon dilakukan terhadap sifat kekuatan tarik, perpanjangan putus, perpanjangan tetap $50 \%$, kekuatan sobek, kekerasan, obot jenis dan ketahanan retak lentur sesuai dengan persyaratan uji menuut SII 0944 - 84; sol karet untuk masing-masing pengujian. Hasil uji vulkaisat dari masing-masing kompon pada formula dibandingkan dengan peryaratan mutu sol sepatu yang terdapat dalam SNI 0778 - 89 - A; Sol karet retak untuk sepatu kanvas dan SNI 1844 - 90 - A; Sol karet cetak sepatu olah aga lihat tabel 2 dan 3. Sedangkan CNS 68531 - 742. S. 2010; Testing stanlart for shoes (canvas high tops) dan KS.N 6522 - 74; Canvas shoes with ruber soles digunakan sebagai pembanding hasil uji selanjutnya lihat tabel 4 .

\section{HASIL DAN PEMBAHASAN}

1. Sifat kenampakan kompon (organoleptis)

Dari 36 kali proses komponding yang dilaksanakan dalam penelitian yang menggunakan paraffinic oil sebagai bahan pelunak, pencampuran bahan pelunak cukup baik dan tidak terjadi pengeluaran minyak kerermukaan kompon dan vulkanisat kompon. Warna kompon dan vulkansat sesuai dengan warna pigmen yang digunakan dengan penambahan tin oksida 1,0 phr. Menurut Krisha - 1990, tingkat kecocokan antara minyak pelunak dengan karet sangat tergantung dari kesamaan daya kohesi karet, dengan minyak. Semakin baik tingkat kecocokan antara minyak pelunak dengan karet, semakin banyak pula pelunak tercampur dalam karet. Bila pelunak tidak cocok dengan karet, minyak pelunak akan merembes keluar ke permukaan dan menyebabkan permukaan kompon akan sticky (mudah lepas bila ditempelkan satu sama lain), sehingga daya lengket akan berkurang bila ditempelkan pada bahan lain.

Dengan demikian dapat dikatakan pencampuran minyak pelunak paraffinic oil Pertamina dengan karet mempunyai tingkat homogenitas pen-campuran yang baik.

2. Sifat fisis vulkanisat kompon.

Untuk lebih mengetahui sifat kemampuan kompon yang menggunakan paraffinic oil Pertamina sebagai bahan pelunak, maka perlu dilakukan uji sifat fisis vulkanisat kompon. Sehingga daya guna kompon dapat tergambar dengan jelas jika dibandingkan dengan persyaratan mutu kompon yang ada.

Hasil uji sifat fisis Vulkanisat kompon untuk masing-masing peny. gunaan paraffinic 60 dan paraffinic 95 dapat dilihat dalam tabel 2 dan 3

Dari tabel 2 dan 3 semua hasil uji vulkanisat kompon memenuhi persyaratan mutu SNI 0778 - 89 - A; sol karet cetak untuk sepatu kanvas dan SNI 1844 - 90 - A; Sol karet cetak sepatu olah raga, kecuali untuk ketahanan kikis sol sepatu untuk olah raga yang syarat mutunya maksimum $1,00 \mathrm{~mm}^{3} / \mathrm{kgm}$ dimana hasil uji vulkanisat kompon terendah adalah $1,36 \mathrm{~mm}^{3} / \mathrm{kgm}$ pada penggunaan $8 \mathrm{phr}$ paraffinic 95 type 2 . Dibandingkan dengan persyaratan mutu sepatu kanvas yang ditentukan oleh Standar Korea (KSM) dan China (CSN) yang hanya menentukan syarat mutu kekuatan tarik dan perpanjangan putus maka hasil uji vulkanisat kompon jauh lehih baik dari persyaratan yang ditentukan (lihat tabel 4). 
patu kanvas umum maupun sol sepatu olah raga dari karet yang meng gunakan minyak pelunak jenis lain yang menghasilkan sifat ketahanan kikis yang juga tidak memenuhi persyaratan mutu, sedangkan sifat fisis lainnya memenui persyaratan mutu. Seperti penggunaan napthanic oil 2 phr sebagai bahan pelunak menghasilkan ketahanan kikis $1,43-2.04$ $\mathrm{mm}^{3} / \mathrm{kgm}$ (Soepranoto 1987) dan penggunaan napthanic oil 6 - 10 phr menghasilkan ketahanan kikis 1,6715-2,7939 $\mathrm{mm}^{3} / \mathrm{kgm}$ (Titien Sayekti. 1990). Sedangkan hasil uji sol karet untuk sepatu olah raga yang ada di pasaran yang dihasilkan oleh beberapa pabrik, ketahanan kikis antara $1,6899-2.1219 \mathrm{~mm}^{3} / \mathrm{kgm}$ (Usodo, 1989)

Berdasarkan hasil data uji tersebut diatas dan dibandingkan dengan hasil penelitian terdahulu dapat dikatakan bahwa paraffinic oil Per. tamina dapat digunakan untuk bahan pelunak dalam pembuatan kompon sol sepatu kanvas yang mempunyai mutu yang sama dengan bahan pelunak import.

Pengaruh paraffinic oil terhadap sifat fisis kompon

Menurut Ridha - 1990, bahan pelunak tidak bereaksi secara kimia dengan karet, tetapi berpengaruh terhadap sifat-sifat kompon atau barang jadi karet. Bahan pelunak berfungsi sebagai pelemas antar molekul atau partikel yang akan memberikan kenaikan dan penurunan sifat fisis kompon.

Dari hasil uji sifat fisis kompon yang menggunakan paraffinic oil yang bervariasi antara $2-8$ phr lihat tabel 2 dan 3 , setelah dilakukan analisa statistik metoda faktorial menghasilkan sebagai berikut :

a. Penambahan $2-8$ phr paraffinic oil dengan jenis dan periakuan yang berbeda akan menghasilkan sifat kekuatan tarik dan ketahanan sobek vulkanisat kompon yang berbeda atau mempunyai hubungan yang sangat nyata pada $\mathrm{P} \leq 0,01$. makin banyak penambahan paraffinic oil akan menghasilkan kekuatan tarik dan ketahanan sobek yang semakin kecil.

b. Penambahan $2-8 \mathrm{phr}$ paraffinic oil dengan jenis, type dan periakuan yang berbeda tidak mempengaruhi sifat perpanjangan putus, perpanjangan tetap $50 \%$, kekerasan, ketahanan kikis dan bobot jenis vulkanisat kompon atau tidak mempunyai hubungan yang sangat nyata pada $P \leq 0,01$

Majalah Barang Kulit, Karet Dan Plastik
Berdasarkan percobaan yang dilakukan ternyata paraffinic oil yang diproduksi Pertamina dapat digunakan untuk bahan pelunak dalam pembuatan kompon sol karet untuk sepatu kanvas karena :

1. Tingkat kecocokan bahan pelunak paraffinic oil dengan karet sangat baik ini ditandai dengan tidak adanya pengeluaran minyak kepermukaan kompon dan vulkanisat kompon.

2. Semua hasil uji vulkanisat memenuhi semua persyaratan mutu yang ditetapkan dalam SNI 1844 - 90 - A dan SNI 07788 - 89 - A, kecuali sifat ketahanan kikis untuk sol sepatu olah raga yaitu maksimum $1,00 \mathrm{~mm}^{3} / \mathrm{kg}$ dibandingkan dengan hasil penelitian paling rendah $1,36 \mathrm{~mm}^{3} / \mathrm{kgm}$ dan tertinggi $2,32 \mathrm{~mm}^{3} / \mathrm{kgm}$.

3. Pengaruh penambahan bahan pelunak paraffinic oil terhadap sifat fisis kompon karet mempunyai hubungan atau berpengaruh sangat nyata terhadap kekuatan tarik dan ketahanan sobek vulkanisat kompon. Makin banyak penambahan paraffinic oil dalam kompon main menurun kekuatan tarik dan ketahanan sobek.

\section{DAFTAR PUSTAKA}

1. Ena Sutrisna W. Processing oil Pertamina sebagai bahan penunjang dalam pengembangan produksi barang karet, Proceeding Pertemuan Teknis Pengembangan Produksi barang Karet, BBKKP, Yogyakarta, 25 Pebruari 1992.

2. Endin, ZA Proses Pembuatan, Kemampuan Produksi dan Reliability of supply Processing Oil Kilang Cilacap, Proseeding Lokakarya Processing Oil, PPM Petrokimia Pertamina, Jakarta, 1990.

3. Kisha Surya Bhuana dan Agustinus Soemadi, Study Perbandingan Penggunaan Processing Oil Pertamina dan Dutrex sebagai minyak Proses Dalam Pembuatan Kompon Telapak Ban dan Bantalan Jambatan, Proceeding Lokakarya Processing Oil, PPM Petrokimia Pertamina, Jakarta, 1990.

4. Morton, Maurica, Rubber Technology, Reinhald Publishing Corporation, New York, 1963.

5. Ridha Arizal, DR, M.Sc, Pengaruh Hasil Analisa Kimia Bahan Pelunak Minyak Terhadap Kompon dan Vulkanisat Karet, Proceeding Lokakarya Processing Oil, PPM Petrokimia Pertamina, Jakarta, 1990.

6. Suparman, Ir., Cara Pengujian dan Analisa Processing Oil Labciutorium Pertamina UP - IV, Proceeding Lokakarya Processing Oil, PPM Petrokimia Pertamina, Jakarta, 1990.

VOL VIII No. 15 Tahun 1992/1993 
Soepranoto, Drs dkk. Penelitian Pembuatan Kompon Karet untuk Sol dan Foxing Sepatu Kanvas, BBKKP, Yogyakarta, 1987.

Suwarti Suseno, RS.,DR.Ir, Manfaat bahan Pembantu Produk Dalam Negeri untuk Industri Karet, Proceeding Lokakarya Processing Oil, PPM Petrokimia Pertamina, Jakarta, 1990.

Titien Sayekti, Ir dkk, Penelitian Kompon Sol Karet Cetak sepatu Kanvas Untuk olah raga, Proceeding Pertemuan Teknis Perkembangan Produk Karet, BBKKP, Yogyakarta, 1991.

Usodo, B.Sc. dkk. Penelitian Pengaruh Cuaca Terhadap Sol Karet Cetak Sepatu Olah raga dengan WOM dan Cuaca Udara Luar, BBKKP, Yogyakarta, 1989.
Tabel 2. Hasil uji rata-rata sifat fisis vulkanisat kompon karet yang menggunakan paraffinic 60

\begin{tabular}{|c|c|c|c|c|c|c|c|c|}
\hline \multirow{2}{*}{ Pengujian } & \multicolumn{2}{|c|}{ Persyaratan SNI } & \multicolumn{3}{|c|}{ Paraffinic 60.0} & \multicolumn{3}{|c|}{ Paraffinic 60.3} \\
\hline & $1844-90-\mathrm{A}$ & 0778-89-A & A & B & C & A & B & C \\
\hline \multirow{4}{*}{$\begin{array}{l}\text { Kekuatan } \\
\text { Tarik, N/mm2 }\end{array}$} & \multirow{4}{*}{$\min .10$} & \multirow{4}{*}{$\min .4 .90$} & 21,10 & 19,49 & 19,55 & 20,27 & 19,43 & 19,22 \\
\hline & & & 21,14 & 19,53 & 20,89 & 23,02 & 22,95 & 20,07 \\
\hline & & & 21,12 & 19,47 & 20,21 & 21,54 & 21,23 & 19,58 \\
\hline & & & 21,12 & 19,50 & 20,22 & 21,61 & 21,20 & 19,62 \\
\hline \multirow{4}{*}{$\begin{array}{l}\text { Perpanjangan } \\
\text { purus, \% }\end{array}$} & \multirow{4}{*}{$\min .250$} & \multirow{4}{*}{$\min .100$} & 720 & 630 & 666 & 586 & 634 & 632 \\
\hline & & & 782 & 636 & 708 & 668 & 724 & 700 \\
\hline & & & 749 & 598 & 698 & 596 & 656 & 700 \\
\hline & & & 750 & 621 & 691 & 600 & 671 & 677 \\
\hline \multirow{4}{*}{$\begin{array}{l}\text { Perpanjangan } \\
\text { tetap } 50 \%, \%\end{array}$} & \multirow{4}{*}{ maks. 4,00} & \multirow{4}{*}{ maks. 10,0} & 1,53 & 1,50 & 1,56 & 1,90 & 1,82 & 1,44 \\
\hline & & & 1,79 & 1,80 & 1,76 & 1,80 & 1,84 & 1,53 \\
\hline & & & 1,68 & 1,44 & 1,62 & 1,92 & 1,80 & 1,54 \\
\hline & & & 1,67 & 1.58 & 1,65 & 1,87 & 1,82 & 1,50 \\
\hline \multirow{4}{*}{$\begin{array}{l}\text { Kekuatan } \\
\text { Sobek, } \\
\text { N/mm2 }\end{array}$} & \multirow{4}{*}{$\min .5,80$} & \multirow{4}{*}{$\min .2,54$} & 13,33 & 13,25 & 12,05 & 11,84 & 14,57 & 10,94 \\
\hline & & & 17,02 & 14,64 & 12,05 & 14,13 & 15,39 & 8,71 \\
\hline & & & 17,26 & 13,52 & 12,42 & 12,31 & 13,15 & 9,99 \\
\hline & & & 15,87 & 13,81 & 12,17 & 12,76 & 14,37 & 9,88 \\
\hline \multirow{4}{*}{$\begin{array}{l}\text { Kekerasan, } \\
\text { shore A }\end{array}$} & \multirow{4}{*}{$50-70$} & \multirow{4}{*}{$55-75$} & 64,00 & 64,00 & 66,00 & 68,00 & 68,00 & 66,00 \\
\hline & & & 63,00 & 64,00 & 65,00 & 69,00 & 67,00 & 67,00 \\
\hline & & & 62,00 & 64,00 & 67,00 & 69,00 & 67,00 & 67,00 \\
\hline & & & 63,00 & 64,00 & 66,00 & 68,67 & 67,33 & 66,67 \\
\hline \multirow{4}{*}{$\begin{array}{l}\text { Ketahanan } \\
\text { kikis, } \\
\text { mm3/kgm }\end{array}$} & \multirow{4}{*}{ maks. 1,00} & \multirow{4}{*}{ maks. 2,50} & 2,32 & 2,52 & 1,58 & 1.55 & 2,19 & 1,75 \\
\hline & & & 2,02 & 2,32 & 1,64 & 1,61 & 2,02 & 1,63 \\
\hline & & & 1,29 & 2,12 & 1,48 & 1,48 & 2,12 & 1,82 \\
\hline & & & 2,09 & 2,32 & 1,57 & 1,55 & 2,11 & 1,73 \\
\hline \multirow{4}{*}{$\begin{array}{l}\text { Bobot jenis, } \\
\mathrm{gr} / \mathrm{cm} 3\end{array}$} & \multirow{4}{*}{ maks. 1.30} & \multirow{4}{*}{ maks. 1,50} & 1,29 & 1,28 & 1,31 & 1,31 & 1,29 & 1,29 \\
\hline & & & 1,30 & 1,32 & 1,29 & 1,32 & 1,28 & 1,31 \\
\hline & & & 1,27 & 1,26 & 1,30 & 1,28 & 1,30 & 1,28 \\
\hline & & & 1,29 & 1,29 & 1,30 & 1,30 & 1,28 & 1,29 \\
\hline $\begin{array}{l}\text { Ketahanan } \\
\text { retak lentur, } \\
250 \text { kcs }\end{array}$ & $\begin{array}{l}\text { tidak } \\
\text { retak }\end{array}$ & $\begin{array}{l}\text { tidak } \\
\text { retak }\end{array}$ & $\begin{array}{l}\text { tidak } \\
\text { retak }\end{array}$ & $\begin{array}{l}\text { tidak } \\
\text { retak }\end{array}$ & $\begin{array}{l}\text { tidak } \\
\text { retak }\end{array}$ & $\begin{array}{l}\text { tidak } \\
\text { retak }\end{array}$ & $\begin{array}{l}\text { tidak } \\
\text { retak }\end{array}$ & $\begin{array}{l}\text { tidak } \\
\text { retak }\end{array}$ \\
\hline
\end{tabular}


Tabel 3. Hasil uji rata-rata sifat fisis vulkanisat kompon karet yang menggunakan paraffinic 95

\begin{tabular}{|c|c|c|c|c|c|c|c|c|}
\hline \multirow{2}{*}{ Pengujian } & \multicolumn{2}{|c|}{ Persyaratan SNI } & \multicolumn{3}{|c|}{ Paraffinic 60.0} & \multicolumn{3}{|c|}{ Paraffinic 60.3} \\
\hline & $1844-90-\mathrm{A}$ & 0778-89-A & A & B & C & A & B & C \\
\hline \multirow{4}{*}{$\begin{array}{l}\text { Kekuatan } \\
\text { Tarik, } \\
\text { N/mm2 }\end{array}$} & \multirow{4}{*}{$\min .10$} & \multirow{4}{*}{$\min .4 .90$} & 17,96 & 19.55 & 20,25 & 21,03 & 20,41 & 18,82 \\
\hline & & & 20,81 & 19,95 & 18,59 & 21,00 & 20,81 & 18,34 \\
\hline & & & 19,53 & 19,73 & 19,93 & 21,07 & 20,59 & 18,61 \\
\hline & & & 19,43 & 19,74 & 19,59 & 21,07 & 20,60 & 18,59 \\
\hline \multirow{4}{*}{$\begin{array}{l}\text { Perpanjangan } \\
\text { purus, } \%\end{array}$} & \multirow{4}{*}{$\min .250$} & \multirow{4}{*}{$\min .100$} & 598 & 678 & 668 & 668 & 728 & 716 \\
\hline & & & 668 & 708 & 612 & 644 & 694 & 696 \\
\hline & & & 621 & 698 & 637 & 649 & 701 & 705 \\
\hline & & & 629 & 655 & 739 & 654 & 705 & 706 \\
\hline \multirow{4}{*}{$\begin{array}{l}\text { Perpanjangan } \\
\text { tetap } 50 \%, \%\end{array}$} & \multirow{4}{*}{ maks. 4,00} & \multirow{4}{*}{ maks. 10,0} & 2,76 & 2,76 & 1,52 & 2,00 & 2,30 & 1,48 \\
\hline & & & 2,28 & 2,57 & 1,62 & 1,93 & 2,02 & 1,59 \\
\hline & & & 2,30 & 2,43 & 1,47 & 1,80 & 1,98 & 1,65 \\
\hline & & & 2,45 & 2,59 & 1,54 & 1,91 & 2,10 & 1.57 \\
\hline \multirow{4}{*}{$\begin{array}{l}\text { Kekuatan } \\
\text { Sobek, } \\
\text { N/mm2 }\end{array}$} & \multirow{4}{*}{$\min .5,80$} & \multirow{4}{*}{$\min .2,54$} & 9,99 & 13,15 & 9,49 & 13,12 & 13,25 & 12,14 \\
\hline & & & 13,08 & 13,24 & 10,03 & 14,29 & 12,24 & 10,89 \\
\hline & & & 10.13 & 10,43 & 9,36 & 11,61 & 12,18 & 9,34 \\
\hline & & & 11,07 & 12,27 & 9,63 & 13,01 & 12,56 & 10,79 \\
\hline \multirow{4}{*}{$\begin{array}{l}\text { Kekerasan, } \\
\text { shore A }\end{array}$} & \multirow{4}{*}{$50-70$} & \multirow{4}{*}{$55-75$} & 70,00 & 65,00 & 64,00 & 67,00 & 65,00 & 63,00 \\
\hline & & & 70,00 & 66,00 & 65,00 & 68,00 & 65,00 & 62,00 \\
\hline & & & 70.00 & 65,00 & 66,00 & 69,00 & 66,00 & 62,00 \\
\hline & & & 70,00 & 65,33 & 65,00 & 68,0 & 65,33 & 62,33 \\
\hline \multirow{4}{*}{$\begin{array}{l}\text { Ketahanan } \\
\text { kikis, } \\
\text { mm3/kgm }\end{array}$} & \multirow{4}{*}{ maks. 1,00} & \multirow{4}{*}{ maks. 2,50} & 2,04 & 2,00 & 1,32 & 1,84 & 2,62 & 1,75 \\
\hline & & & 2,08 & 1,92 & 1,45 & 1,73 & 2,12 & 1,82 \\
\hline & & & 1,98 & 2,10 & 1,30 & 1,63 & 1,93 & 1,63 \\
\hline & & & 2,03 & 2,01 & 1,36 & 1,73 & 2,10 & 1,73 \\
\hline \multirow{4}{*}{$\begin{array}{l}\text { Bobot jenis, } \\
\mathrm{gr} / \mathrm{cm} 3\end{array}$} & \multirow{4}{*}{ maks. 1.30} & \multirow{4}{*}{ maks. 1,50} & 1,32 & 1,28 & 1,32 & 1,30 & 1,28 & 1,28 \\
\hline & & & 1,30 & 1,39 & 1,31 & 1,31 & 1,27 & 1,27 \\
\hline & & & 1,31 & 1,32 & 1,33 & 1,28 & 1,30 & 1,31 \\
\hline & & & 1,31 & 1,30 & 1,32 & 1,30 & 1,28 & 1,29 \\
\hline $\begin{array}{l}\text { Ketahanan } \\
\text { retak lentur, } \\
250 \text { kcs }\end{array}$ & $\begin{array}{l}\text { tidak } \\
\text { retak }\end{array}$ & $\begin{array}{l}\text { tidak } \\
\text { retak }\end{array}$ & $\begin{array}{l}\text { tidak } \\
\text { retak }\end{array}$ & $\begin{array}{l}\text { tidak } \\
\text { retak }\end{array}$ & $\begin{array}{l}\text { tidak } \\
\text { retak }\end{array}$ & $\begin{array}{l}\text { tidak } \\
\text { retak }\end{array}$ & $\begin{array}{l}\text { tidak } \\
\text { retak }\end{array}$ & $\begin{array}{l}\text { tidak } \\
\text { retak }\end{array}$ \\
\hline
\end{tabular}

Tabel 4. Persyaratan mutu sol sepatu dari beberapa negara

\begin{tabular}{|c|c|c|c|c|c|c|}
\hline \multirow{3}{*}{ No. } & \multirow{3}{*}{ Test item } & \multicolumn{3}{|c|}{ CNS 6831 } & \multicolumn{2}{|c|}{ KS.M 652274} \\
\hline & & \multirow{2}{*}{$\begin{array}{c}742.5: \\
2009\end{array}$} & \multicolumn{2}{|c|}{ 743. S. 2010} & \multirow{2}{*}{ Soft } & \multirow{2}{*}{ Hard } \\
\hline & & & all numbers & large & & \\
\hline $\begin{array}{l}2 \\
3\end{array}$ & $\begin{array}{l}\text { Tensile strength, } \\
\mathrm{kg} / \mathrm{cm} 2 \\
\mathrm{~N} / \mathrm{mm} 2 \\
\text { Elongation, } \\
\\
\text { Aging resistance } \\
\text { property, \% }\end{array}$ & $\begin{array}{l}\min . \\
65 \\
6,37 \\
\min . \\
330 \\
-\end{array}$ & $\begin{array}{l}\min . \\
90 \\
8,83 \\
\min . \\
150 \\
-\end{array}$ & $\begin{array}{c}\min . \\
150 \\
14,71 \\
\min . \\
450 \\
-\end{array}$ & $\begin{array}{c}\text { min. } \\
60 \\
5,88 \\
\text { min. } \\
300 \\
\text { maks. } \\
20\end{array}$ & $\begin{array}{c}\min . \\
60 \\
5,88 \\
- \\
\text { maks. } \\
20\end{array}$ \\
\hline
\end{tabular}

Keterangan :

CNS 69531 - 742. s. 2009 : Testing standard for sport shoes.

CNS 69531 - 743. S. 2010 : Testing standard for sport shoes.

(canvas high tops)

KS M $6522 \cdot 74$

: Canvas shoes with rubber sole

Tabel 5 Typical Properties Paraffinic oil Pertamina

\begin{tabular}{|c|l|c|c|c|}
\hline \multirow{2}{*}{ No. } & \multicolumn{1}{|c|}{ Properties } & $\begin{array}{c}\text { Metode } \\
\text { ASTM } \\
\end{array}$ & D & \multicolumn{2}{|c|}{ Paraffinic } \\
\cline { 3 - 5 } & & 1500 & 60 & 95 \\
\hline 1 & Colour & 1298 & 0,5 & 0,5 \\
2 & Spes. Grafity 60.60 oF & 97 & 0,8711 & 0,8767 \\
3 & Pour Point, oF & $+5,0$ & $+15,0$ \\
4 & Flash Point, oF & 445 & 425 & 253 \\
5 & Kinematic Viscosity\}at 100 oF, & & 27,05 & 54,18 \\
& Cst & & 4,74 & 7,29 \\
& at 210 oF, Cst & 1218 & 1,4768 & 1,4820 \\
7 & Refractif Index at 220 oC & Aniline point, oC & 99,5 & 105,0 \\
8 & Vis. Gravity Constant & 2501 & 0,2808 & 0,8085 \\
\hline
\end{tabular}

Sumber : Suparman - 1990 (6) 